\title{
Characteristics of fast-food/takeaway-food and restaurant/ café-food consumers among New Zealand adults
}

\author{
Claire Smith ${ }^{1, *}$, Andrew Robert Gray ${ }^{2}$, Elizabeth Ann Fleming ${ }^{1}$ and \\ Winsome Ruth Parnell \\ 'Department of Human Nutrition, University of Otago, PO Box 56, Dunedin 9054, New Zealand: \\ ${ }^{2}$ Department of Preventive and Social Medicine, University of Otago, Dunedin, New Zealand
}

Submitted 12 March 2013: Final revision received 13 August 2013: Accepted 28 August 2013: First published online 8 0ctober 2013

\begin{abstract}
Objective: To investigate: (i) the percentage of the New Zealand (NZ) population reporting fast food/takeaway food and restaurant/café food per day; (ii) examine demographic factors associated with their use; (iii) quantify their contribution to energy intake; and (iv) describe the specific types of foods reported from both sources.

Design: Twenty-four hour diet recalls from the cross-sectional 2008/09 NZ Adult Nutrition Survey were used to identify fast-food and restaurant-food consumers. Setting: NZ households.

Subjects: Adults aged 15 years and older ( $n$ 4721).

Results: Overall $28 \%$ reported consuming at least one fast food and $14 \%$ a restaurant food within the $24 \mathrm{~h}$ diet recall. Fast-food consumption was not associated with level of education or an area-based measure of socio-economic status, but a higher education was positively associated with restaurant-food consumption. Individual factors such as ethnicity, household size, age, sex and marital status were found to be important influences on the use of fast food and restaurant food. Fast-food consumption was more prevalent among participants living in urban areas, young adults (19-30 years) and Māori compared with NZ European and Others. The most frequently reported fast foods were bread-based dishes, potatoes (including fries) and non-alcoholic beverages.

Conclusions: Given the high reported consumption of fast food by young adults, health promotion initiatives both to improve the nutritional quality of fast-food menus and to encourage healthier food choices would likely make a large impact on the overall diet quality of this group.
\end{abstract}

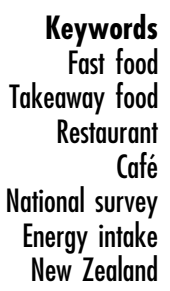

International research documents the increasing importance of food prepared outside the home to the modern diet. Included in this are foods purchased from fast-food outlets, takeaway outlets, restaurants and cafés. A higher density of fast-food and takeaway outlets has been documented in more socio-economically deprived areas overseas $^{(1-4)}$ and in New Zealand (NZ) ${ }^{(2)}$. Fast foods in particular have been described as a contributing factor to the increase in obesity rates; however, the evidence is inconsistent with some studies reporting a positive association $^{(5-7)}$ and others reporting no association ${ }^{(8-10)}$. Fast food is only one type of food prepared outside the home and research in the USA has shown the demographic profile of restaurant- and café-food consumers differs from that of fast-food consumers ${ }^{(11)}$.

In 2009, one-quarter of estimated household food expenditure in NZ was for restaurant, café, takeaway and fast food ${ }^{(12)}$. Furthermore, the 2012 NZ Health and Lifestyle Survey reported that one-third of the population purchased 'takeaways' and 14\% used 'dine-in venues' at least weekly ${ }^{(13)}$. To our knowledge there is no published research in NZ that has documented individual, household and socio-economic factors associated with the consumption of fast food/takeaway food and restaurant/café food. Understanding both who consumes these foods and also what is consumed is important to tailor the development of appropriate public health strategies. The $24 \mathrm{~h}$ diet recall of the cross-sectional 2008/09 New Zealand Adult Nutrition Survey (2008/09 NZANS) provides information on where participants sourced their food ${ }^{(14)}$.

Given the potential contribution of fast food and restaurant food to the $\mathrm{NZ}$ diet, the objectives of the current research were to: (i) document the percentage of the population reporting fast food/takeaway food and restaurant/café food per day; (ii) examine demographic factors associated with their use; (iii) quantify their contribution to energy intake; and (iv) describe the specific types of foods reported from both sources. 


\section{Methods}

\section{Study design and sample}

The 2008/09 NZANS was a cross-sectional survey using a national sample of adults (aged 15 years and older) ${ }^{(14)}$. A three-stage, stratified, probability-proportional-to-size sample design was used with an overall response rate of $61 \%$ ( $n$ 4721). Māori and Pacific ethnic groups and the age groups 15-18 years and 71 years and above were over-sampled. All participants gave informed consent. A full description of the methods has been documented elsewhere $^{(14)}$.

\section{Classification of the fast-food and restaurant- food consumer}

Participants completed a four-stage $24 \mathrm{~h}$ diet recall administered by trained interviewers using LINZ24 (a computer software system) $)^{(14)}$. A randomly selected sub-sample (25\%) completed a second $24 \mathrm{~h}$ diet recall; however, we have only reported on the first day of recall. Although the aim was for all days of the week to be equally represented this was not achieved, with a lower number of interviews completed on weekend days ${ }^{(14)}$. In the initial stage of the diet recall, a 'quicklist' of all foods, drinks and dietary supplements was collected. Interviewers asked where each item was sourced, using the following options: (i) store/ shop/market; (ii) restaurant/café; (iii) fast-food/takeaway outlet; (iv) workplace (cafeteria, catering); (v) vending machine; (vi) other (community food programme, gift, online purchases); and (vii) home/domestic (home-grown produce). Participants who reported at least one food or beverage sourced from a fast-food/takeaway outlet on their day's recall were classified as a 'fast-food consumer', and those reporting at least one food or beverage from a restaurant/café were classified as a 'restaurant-food consumer'. In the second and third stages of the recall a detailed description of all foods and beverages was collected with information on the amounts consumed. In the fourth stage the foods were reviewed in chronological order. For the calculation of energy and nutrient intakes, foods were matched to the NZ Food Composition Database ${ }^{(14)}$.

\section{Demographic predictors of fast-food and restaurant-food consumption}

Demographic variables were selected a priori, after a review of the literature, and included: age, sex, ethnicity, level of education, marital status, household size (one, two, three, and four or more persons), area-based socioeconomic status and area of residence (rural $v$. urban). Participants were categorised into one of three ethnic groups based on self-identification. If participants reported belonging to two or more groups then they were assigned to a single group using the following order: (i) Māori; (ii) Pacific; and (iii) NZ European and Others (NZEO). Marital status was defined as single (not currently living with a partner or spouse) or married/de facto (living with a partner or spouse).

Participants reported their highest school-level qualification, and if applicable their highest post-school qualification (greater than 3 months' study or training). Four groups were derived: (i) no school or post-school qualifications; (ii) school qualifications only; (iii) trade or technical qualification; and (iv) post-school qualification (professional or tertiary).

Area-based socio-economic status was measured using the 2006 NZ Index of Deprivation (NZDep06). This measure of deprivation combines nine variables from the NZ census that reflect eight dimensions of material and social deprivation $^{(15)}$. It provides a score from 1 to 10 for each meshblock in $\mathrm{NZ}^{(16)}$. A meshblock is a geographical location in NZ defined by Statistics NZ, each containing around sixty households in rural areas and 110 households in urban areas ${ }^{(16)}$. For the 2008/09 NZANS, these scores were divided into quintiles. Participants living in quintile I resided in the least deprived areas and those in quintile $\mathrm{V}$ resided in the most deprived areas.

To classify participants as living in either a rural or an urban location, each participant was categorised into one of seven groups based on the location of the meshblock where they resided. The rural classification takes into account both proximity to urban areas and also dependence (in terms of employment) on urban areas ${ }^{(17)}$. The seven groups were collapsed into three groups: (i) urban; (ii) rural with some urban influence; and (iii) rural with low/no urban influence.

\section{Types of fast foods and restaurant foods}

Each food item reported in the $24 \mathrm{~h}$ diet recall was assigned to one of 540 subgroups which were collapsed into thirty-two main food groups ${ }^{(14)}$. The top ten food groups contributing to daily total energy that were sourced from fast-food/takeaway outlets and restaurants/cafés were identified and are listed in Table 1. As the food group 'bread-based dishes' included a wide variety of dishes (e.g pizza, sandwiches and burgers) frequently noted as being sourced from a fast-food/takeaway outlet, foods within this food group were examined at the subgroup level.

\section{Statistical methods}

Survey commands were used to allow for the complex survey design, including sampling weights and primary sampling units. Results reported have been weighted to reflect population estimates.

As fast-food consumption has been found to be higher on Friday ${ }^{(18)}$ and Saturday ${ }^{(11)}$, and as the number of interviews conducted on weekend days was lower than for other days ${ }^{(14)}$, the prevalence of fast-food and restaurant-food consumption was estimated with and without adjustment for day of the week. Energy intake from fast food and restaurant food was calculated for the population and for consumers only. 
Table 1 Examples of food items included in the most frequently reported fast foods and restaurant foods

\begin{tabular}{ll}
\hline Food group* & Examples of food items included \\
\hline Grains and pasta & Rice (fried/risotto), flour, pasta, bran, cereal-based products and dishes (lasagne) \\
Bread & All types bread (rolls, pita, focaccia, garlic), bagels, crumpets, sweet buns \\
Cakes and muffins & All cakes and muffins, slices, scones, pancakes, doughnuts, pastry, cake bars \\
Bread-based dishes & Sandwiches, filled rolls, hamburgers, hotdogs, pizza, nachos, doner kebabs, wontons, spring rolls \\
Pies and pasties & All pies including potato top, pasties, savouries, sausage rolls, quiche with pastry \\
Fish and seafood & All fish (canned, battered, fingers, etc.), shellfish, squid, crab, fish/seafood dishes (pies, casseroles, \\
fritters), fish/seafood products & All vegetables including mixes, coleslaw, tomatoes, green salads, legumes and pulses, legume \\
Vegetables & products and dishes, vegetable dishes \\
Potatoes, kumara and taro & Mashed, boiled, baked, scalloped potatoes and kumara, hot chips, crisps, hash browns, taro roots \\
Poultry & and stalks \\
Non-alcoholic beverages & All chicken, duck, turkey and muttonbird muscle meats (breast, leg, wing, etc.) and processed meat, \\
stews and stir-fries & All teas, coffee and substitutes, hot chocolate, juices, cordial, soft drinks, water, powdered drinks, \\
Alcoholic beverages & sports and energy drinks
\end{tabular}

${ }^{*}$ Table adapted from the Methodology Report for the 2008/09 New Zealand Adult Nutrition Survey, which also provides a full list of all food groups ${ }^{(14)}$.

Logistic regression was performed to estimate unadjusted odds ratios and $95 \%$ confidence intervals for fast-food and restaurant-food consumption for each demographic variable. Multiple logistic regression was used to produce adjusted odds ratios and 95\% confidence intervals with all variables entered into the model. Interactions were tested for age group-by-sex, sex-by-marital status and ethnicity-byage group.

Logistic regression (unadjusted) was also used to examine sex, ethnicity and age group differences in the types of fast foods and restaurant foods reported among consumers.

The statistical software package Stata 12 was used for all statistical analyses. All statistical tests were two-sided and $P<0.05$ was considered statistically significant in all cases.

\section{Results}

Table 2 describes the characteristics of the 2008/09 NZANS population. Adjustment for day of the week did not alter the prevalence estimates for fast-food or restaurant-food consumption, therefore unadjusted values are presented. On the day of the first recall, $28 \%$ reported a fast food and $14 \%$ a restaurant food. After excluding those reporting only beverages, the percentage of the population who reported fast food and restaurant food decreased to $26 \%$ and $12 \%$, respectively.

The percentage contribution to daily energy from fast food $(8 \cdot 7 \%)$ was higher than from restaurant food $(4 \cdot 1 \%$; Table 3). For fast-food consumers on their recall day $31 \%$ of daily energy intake was from fast food, and this was similar for restaurant-food consumers (Table 3).

\section{Predictors of fast-food and restaurant-food consumption}

There was no evidence of interactions for age group-bysex, sex-by-marital status and ethnicity-by-age group and therefore interaction terms were excluded from the final model. In Table 4, from the full model, females were less likely than males to report fast food (OR $=0 \cdot 77 ; 95 \%$ CI $0 \cdot 63,0 \cdot 95 ; P=0 \cdot 015)$. The relationship between fastfood consumption and age showed an inverse $\mathrm{J}$ shape, peaking in the 19-30 year age group. There was evidence of a difference between ethnicities $(P=0 \cdot 003)$ and Māori were more likely to report fast food compared with both NZEO $(\mathrm{OR}=1 \cdot 47 ; 95 \%$ CI $1 \cdot 15,1 \cdot 89 ; P=0 \cdot 002)$ and Pacific $(\mathrm{OR}=1 \cdot 58 ; 95 \%$ CI $1 \cdot 17,2 \cdot 10 ; P=0 \cdot 002)$, but there was no evidence of a difference between NZEO and Pacific $(P=0.594)$.

There was also evidence of a difference between household sizes $(P=0.010)$. Participants living in households with four or more people had higher odds of reporting fast food compared with both participants living by themselves (OR $=1 \cdot 56,95 \%$ CI $1 \cdot 03,2 \cdot 35 ; P=0 \cdot 035)$ and those living in two-person households $(\mathrm{OR}=1 \cdot 58$; $95 \%$ CI $1 \cdot 18,2 \cdot 11 ; P=0 \cdot 002)$. Area of residence was statistically significant $(P=0 \cdot 008)$ with those living in an urban area twice as likely to report fast food compared with both those in a rural area with some urban influence (OR $=0.50 ; 95 \%$ CI $0.30,0 \cdot 83 ; P=0.008)$ and those in a rural area with low/no urban influence $(\mathrm{OR}=0 \cdot 51$; $95 \%$ CI $0 \cdot 30,0 \cdot 80 ; P<0 \cdot 001)$. The socio-economic variables NZDep06 quintile and level of education were not associated with fast-food consumption.

For restaurant foods, in the full model, there was again evidence of ethnicity effects $(P<0 \cdot 001)$ where Pacific were less likely to report restaurant foods compared with both NZEO $(\mathrm{OR}=0 \cdot 36 ; 95 \% \mathrm{CI} 0 \cdot 21,0 \cdot 60 ; P<0 \cdot 001)$ and Māori $(\mathrm{OR}=0.43 ; 95 \% \mathrm{CI} 0 \cdot 24,0.77 ; P=0 \cdot 005)$. There was evidence of an association with education $(P<0 \cdot 001)$ where participants with post-school qualifications were more likely to report restaurant food compared with both those with no school qualifications (OR $=1 \cdot 88$; 95\% CI $1 \cdot 23,2 \cdot 88 ; P=0 \cdot 004)$ and those with trade qualifications (OR $=2 \cdot 09 ; 95 \%$ CI $1 \cdot 41,3 \cdot 11 ; P<0 \cdot 001)$. In the opposite direction to fast-food consumption, participants living in a 
Table 2 Participant characteristics and the percentage of fast-food/takeaway-food consumers and restaurant/caféfood consumers, 2008/09 New Zealand Adult Nutrition Survey

\begin{tabular}{|c|c|c|c|}
\hline & All & Fast-food consumers & Restaurant-food consumers \\
\hline Demographics & $\% *$ & $\%$ & $\%$ \\
\hline Total sample & & 28 & 14 \\
\hline \multicolumn{4}{|l|}{ Sex } \\
\hline Male & 48 & 31 & 13 \\
\hline Female & 52 & 26 & 15 \\
\hline \multicolumn{4}{|l|}{ Age group } \\
\hline $15-18$ years & 7 & 38 & 7 \\
\hline $19-30$ years & 20 & 42 & 15 \\
\hline $31-50$ years & 37 & 29 & 21 \\
\hline $51-70$ years & 27 & 20 & 14 \\
\hline $71+$ years & 10 & 9 & 16 \\
\hline \multicolumn{4}{|l|}{ Ethnicity } \\
\hline NZEO & 84 & 26 & 15 \\
\hline Māori & 11 & 28 & 10 \\
\hline Pacific & 5 & 32 & 6 \\
\hline \multicolumn{4}{|l|}{ Highest education completedt } \\
\hline No school or post-school qualifications & 18 & 22 & 10 \\
\hline School qualifications only & 27 & 32 & 14 \\
\hline Trade or technical qualification & 22 & 27 & 10 \\
\hline Post-school qualification (professional or tertiary) & 33 & 29 & 19 \\
\hline \multicolumn{4}{|l|}{ NZDep06 quintile } \\
\hline I & 20 & 30 & 17 \\
\hline II & 22 & 26 & 18 \\
\hline III & 21 & 29 & 12 \\
\hline IV & 19 & 27 & 12 \\
\hline V & 18 & 29 & 10 \\
\hline \multicolumn{4}{|l|}{ Household sizet } \\
\hline One person & 12 & 20 & 15 \\
\hline Two persons & 33 & 20 & 16 \\
\hline Three persons & 18 & 29 & 17 \\
\hline Four or more persons & 38 & 37 & 10 \\
\hline \multicolumn{4}{|l|}{ Marital statust } \\
\hline Single & 38 & 32 & 12 \\
\hline Married/de facto & 62 & 26 & 15 \\
\hline \multicolumn{4}{|l|}{ Area } \\
\hline Urban & 87 & 30 & 14 \\
\hline Rural with some urban influence & 6 & 18 & 13 \\
\hline Rural with low/no urban influence & 7 & 18 & 14 \\
\hline \multicolumn{4}{|l|}{ Day of the week } \\
\hline Monday and Tuesday & 35 & 22 & 11 \\
\hline Wednesday and Thursday & 29 & 26 & 15 \\
\hline Friday & 11 & 44 & 16 \\
\hline Saturday and Sunday & 25 & 31 & 16 \\
\hline
\end{tabular}

NZEO, New Zealand European and Others; NZDep06, 2006 NZ Index of Deprivation.

${ }^{*}$ All percentages adjusted for survey weightings to represent the New Zealand population.

tMissing data: highest level of education ( $n 34)$, household size ( $n 26)$, marital status ( $n 27)$.

household with four or more people were half as likely to report restaurant food compared with single-person households ( $\mathrm{OR}=0 \cdot 48 ; 95 \% \mathrm{CI} 0 \cdot 27,0 \cdot 85 ; P=0 \cdot 011)$ and two-person households (OR $=0.57 ; 95 \%$ CI $0.38,0 \cdot 84$; $P=0 \cdot 006)$.

\section{Types of fast foods and restaurant foods}

The types of foods sourced from fast-food outlets and restaurants are shown in Table 5. Bread-based dishes (41\%), potatoes (including hot chips; 37\%) and nonalcoholic beverages (36\%) were the most commonly reported types of fast food. A higher percentage of females reported vegetables (excluding potatoes) compared with males $(P=0.042)$. Māori $(53 \%, P<0 \cdot 001)$ and Pacific (49\%, $P<0.001$ ) were more likely to report potatoes compared with NZEO (33\%). Pacific were also more likely to report poultry compared with NZEO $(26 \% v \cdot 14 \%$, $P=0 \cdot 001$ ). Māori fast-food consumers (18\%) were more likely to report fish/seafood compared with Pacific (11\%, $P=0 \cdot 015)$ and NZEO $(11 \%, P=0 \cdot 014)$. Pacific were more likely to report grains and pasta compared with Māori (18\% v. 9\%, $P=0.022)$.

The percentage reporting bread-based dishes declined with age $(P<0.001)$ but in contrast, the percentage reporting fish/seafood increased with age to $51-70$ years $(P=0 \cdot 007)$. The majority of bread-based dishes sourced from fast-food outlets were sandwiches, burgers or hotdogs.

Nearly one-third of restaurant consumers reported vegetables compared with only $7 \%$ of fast-food consumers. Females were more likely to report cakes and 
Table 3 Contribution to daily energy from fast food and restaurant food overall and for consumers, 2008/09 New Zealand Adult Nutrition Survey

\begin{tabular}{lrcc}
\hline & & \multicolumn{2}{c}{ Contribution to daily energy (\%) } \\
\cline { 3 - 4 } & $n$ & Mean & $95 \% \mathrm{Cl}$ \\
\hline Fast food & & & \\
$\quad$ Total sample & 4721 & $8 \cdot 7$ & $7 \cdot 9,9 \cdot 4$ \\
$\quad$ Consumers* & 1256 & $31 \cdot 0$ & $29 \cdot 4,32 \cdot 6$ \\
Restaurant food & & & $3 \cdot 5,4 \cdot 7$ \\
$\quad$ Total sample & 4721 & $4 \cdot 1$ & $27 \cdot 3,31 \cdot 9$ \\
$\quad$ Consumers & 498 & $29 \cdot 6$ & \\
\hline
\end{tabular}

${ }^{\star}$ Excludes non-reporters (zero values).

muffins compared with males $(27 \% v .12 \%, P<0 \cdot 001)$. In addition, the percentage of participants who reported cakes and muffins increased with age $(P=0 \cdot 001)$. Vegetables were more likely to be reported by NZEO participants compared with Māori (32\% v. 18\%, P=0.009).

A higher percentage of male restaurant-food consumers reported alcoholic beverages compared with females (29\% v. $16 \%, P=0 \cdot 016)$. Over half of restaurant-food consumers and one-third of fast-food consumers reported a nonalcoholic beverage. Reporting only a beverage (with no food) was more common for restaurant-food consumers with $9 \%$ reporting only a non-alcoholic beverage and 9\% reporting only an alcoholic beverage.

\section{Discussion}

Overall, nearly one-third of the NZ population reported consuming a fast food (28\%) and 14\% reported consuming a restaurant food on any one day. Younger adults (19-30 years) were the highest consumers of fast foods and also reported a high consumption of restaurant foods. The contribution of fast food and restaurant food to the NZ diet was lower than in the USA. In NZ, daily energy from fast food was found to be less than $10 \%$, and from restaurants less than 5\%. In the National Health and Examination Survey (NHANES) 2003-2008, adults (20-50 years) were found to source $15 \cdot 9 \%$ of their daily energy from 'quick service restaurants' and 10.4\% from 'full service restaurants'; this was lower for older adults ( 51 years and above) with $8 \cdot 6 \%$ of daily energy from 'quick service restaurants' and 10.4\% from 'full service restaurants, (19).

The current study did not show any association between fast-food consumption and socio-economic status despite the reported higher density of fast-food and takeaway outlets located within more deprived areas of $\mathrm{NZ}{ }^{(2)}$. Similarly, Australian research found no association between an area-based measure of socio-economic status and the use of foods prepared outside the home ${ }^{(8)}$. These findings are important in light of suggestions to restrict the number of fast-food outlets within low socioeconomic areas ${ }^{(20)}$. In the USA, Kim and Leigh reported an inverted U-shaped curve for the relationship between income and fast-food use and suggest this indicates that for the 'poor', supermarket food, rather than fast food, contributes most to the obesity epidemic ${ }^{(11)}$.

There was also no evidence of an association between fast-food consumption and level of education. Fast-food consumption in relation to level of education is inconsistent in the literature, with some studies reporting a higher use of fast food among those with less education ${ }^{(21)}$ and others reporting a lower use ${ }^{(22,23)}$. In contrast, we found that participants with higher levels of education were more likely to be consumers of restaurant foods. Research in NZ among families with children found that the frequency of fast-food and takeaway use was similar by household income level ${ }^{(24)}$. Furthermore, food from restaurants was more likely to be reported by households with a high income compared with a low income ${ }^{(24)}$. Thus, together with the current research, there is evidence that in NZ households of higher socio-economic status are better able to afford foods from restaurants and cafés. These findings are consistent with a recent international review which concluded higher socio-economic groups were more likely to consume foods prepared outside the home ${ }^{(25)}$.

The lower consumption of fast food by those living in rural areas suggests that in NZ physical proximity is a factor in the decision to consume these foods. Few studies have examined differences in fast-food consumption between people living in rural and urban areas. Contrary to our findings, in US 18- to 28-year-olds, fast-food consumption did not differ between people living in 'non-urban', 'low urban' or 'high density urban' areas. This was despite the lower availability of fast food in these areas ${ }^{(26)}$. This inconsistency may be due to a difference in the nature of 'rural' or 'non-urban' areas between the USA and NZ.

Males were higher consumers of fast food in NZ compared with females and this is consistent with international findings ${ }^{(11,23)}$. Females were also more likely to choose vegetables from fast-food sources; indicative of healthier choices compared with males. The higher intake of fast food in the younger age groups in NZ follows international trends ${ }^{(8,11,23,27-29)}$. The $15-18$ year age group was less likely to report fast foods compared with the 19-30 year age group, probably as the younger age group is attending school and likely to be living within a family home where family meals are provided. Factors identified as facilitating fast-food consumption in Australian adults (20 to 45 years) include busy lifestyles, long working hours and not knowing how to $\operatorname{cook}^{(30)}$. Dave et al. also showed a dislike of cooking was negatively associated with age ${ }^{(31)}$. The higher consumption of fast food and restaurant food among young adults may be a life-course or a generational effect but along with Orfanos et al. we cannot discern this from cross-sectional data $^{(9)}$. Possibly younger adults may continue to eat foods they have developed a taste for in later years ${ }^{(32)}$. 
Table 4 Odds ratios and $95 \%$ confidence intervals for any fast-food and any restaurant-food consumption in the previous $24 \mathrm{~h}$ ( $n$ 4687) ${ }^{\star}$, 2008/09 New Zealand Adult Nutrition Survey

\begin{tabular}{|c|c|c|c|c|c|c|c|c|c|c|c|c|}
\hline & \multicolumn{6}{|c|}{ Fast-food consumption } & \multicolumn{6}{|c|}{ Restaurant-food consumption } \\
\hline & \multicolumn{2}{|c|}{ Unadjustedt } & \multirow[b]{2}{*}{$P \S$} & \multicolumn{2}{|c|}{ Adjusted $\neq$} & \multirow[b]{2}{*}{$P \S$} & \multicolumn{2}{|c|}{ Unadjustedt } & \multirow[b]{2}{*}{$P \S$} & \multicolumn{2}{|c|}{ Adjusted‡ } & \multirow[b]{2}{*}{$P \S$} \\
\hline & OR & $95 \% \mathrm{Cl}$ & & OR & $95 \% \mathrm{Cl}$ & & OR & $95 \% \mathrm{Cl}$ & & OR & $95 \% \mathrm{Cl}$ & \\
\hline \multicolumn{13}{|l|}{ Gender } \\
\hline Male & $1 \cdot 00$ & - & 0.022 & $1 \cdot 00$ & - & 0.015 & $1 \cdot 00$ & - & 0.288 & $1 \cdot 00$ & - & $0 \cdot 640$ \\
\hline Female & 0.79 & $0.65,0.97$ & & $0 \cdot 77$ & $0.63,0.95$ & & $1 \cdot 15$ & $0.89,1.48$ & & 1.07 & $0.82,1.39$ & \\
\hline Age group (\%) & & & $<0.001$ & & & $<0.001$ & & & $<0.001$ & & & $0 \cdot 106$ \\
\hline $15-18$ years & $1 \cdot 00$ & - & & 1.00 & - & & $1 \cdot 00$ & - & 0.645 & $1 \cdot 00$ & - & \\
\hline $19-30$ years & $1 \cdot 19$ & $0.89,1.59$ & & $1 \cdot 40^{\mathrm{a}}$ & $0.98,1.98$ & & 2.53 & $1.57,4.05$ & & $1 \cdot 85$ & $1 \cdot 06,3 \cdot 23$ & \\
\hline $31-50$ years & 0.69 & $0.55,0.87$ & & $0 \cdot 87$ & $0.62,1.22$ & & $2 \cdot 29$ & $1 \cdot 48,3 \cdot 56$ & & 1.50 & $0 \cdot 87,2.59$ & \\
\hline $51-70$ years & 0.42 & $0.31,0.56$ & & 0.65 & $0.43,0.98$ & & $2 \cdot 79$ & $1 \cdot 82,4 \cdot 29$ & & 1.58 & $0 \cdot 89,2 \cdot 79$ & \\
\hline $71+$ years & $0 \cdot 17$ & $0 \cdot 12,0 \cdot 24$ & & $0 \cdot 28^{\mathrm{b}}$ & $0 \cdot 18,0 \cdot 44$ & & $2 \cdot 09$ & $1 \cdot 33,3 \cdot 28$ & & $1 \cdot 19$ & $0 \cdot 63,2 \cdot 25$ & \\
\hline Ethnicity & & & $<0.001$ & & & 0.003 & & & $<0.001$ & & & $<0.001$ \\
\hline NZEO & $1 \cdot 00$ & - & & $1 \cdot 00$ & - & & $1 \cdot 00$ & - & 0.645 & 1.00 & - & \\
\hline Māori & $1 \cdot 68$ & $1 \cdot 34,2 \cdot 09$ & & $1 \cdot 47^{\mathrm{a}}$ & $1 \cdot 15,1 \cdot 89$ & & 0.59 & $0.41,0.87$ & & 0.83 & $0 \cdot 56,1 \cdot 24$ & \\
\hline Pacific & $1 \cdot 23$ & $0.99,1.52$ & & $0.93^{\mathrm{b}}$ & $0 \cdot 72,1 \cdot 21$ & & $0 \cdot 24$ & $0.15,0.39$ & & 0.36 & $0.21,0.60$ & \\
\hline Highest education completed & & & 0.002 & & & 0.458 & & & $<0.001$ & & & $<0.001$ \\
\hline No school or post-school qualifications & 1.00 & - & & $1 \cdot 00$ & - & & 1.00 & - & 0.645 & $1 \cdot 00$ & - & \\
\hline School qualifications only & $1 \cdot 67$ & $1 \cdot 28,2 \cdot 19$ & & $1 \cdot 25$ & $0.93,1.69$ & & 1.58 & $1 \cdot 05,2 \cdot 37$ & & $1 \cdot 57$ & $1 \cdot 02,2 \cdot 42$ & \\
\hline Trade or technical qualification & $1 \cdot 33$ & $1 \cdot 00,1 \cdot 75$ & & $1 \cdot 16$ & $0.84,1.59$ & & 1.05 & $0.66,1.69$ & & $0.90^{\mathrm{a}}$ & $0.54,1.50$ & \\
\hline Post-school qualification (professional or tertiary) & 1.45 & $1 \cdot 00,1 \cdot 88$ & & $1 \cdot 23$ & $0.90,1.67$ & & $2 \cdot 28$ & $1 \cdot 54,3 \cdot 36$ & & $1 \cdot 88^{\mathrm{b}}$ & $1 \cdot 23,2 \cdot 88$ & \\
\hline NZDep06 quintile & & & $0 \cdot 737$ & & & 0.479 & & & $<0.001$ & & & 0.055 \\
\hline 1 & 1.00 & - & & $1 \cdot 00$ & - & & $1 \cdot 00$ & - & 0.645 & 1.00 & - & \\
\hline II & 0.83 & $0 \cdot 61,1 \cdot 15$ & & $0 \cdot 90$ & $0 \cdot 64,1 \cdot 27$ & & $1 \cdot 06$ & $0 \cdot 69,1 \cdot 62$ & & $1 \cdot 11$ & $0.73,1.69$ & \\
\hline III & 0.94 & $0 \cdot 67,1 \cdot 32$ & & $0 \cdot 88$ & $0.62,1.25$ & & 0.64 & $0.41,1.02$ & & 0.69 & $0 \cdot 44,1 \cdot 10$ & \\
\hline IV & $0 \cdot 86$ & $0 \cdot 63,1 \cdot 18$ & & $0 \cdot 76$ & $0.55,1.06$ & & 0.67 & $0.42,1.06$ & & $0 \cdot 71$ & $0 \cdot 45,1 \cdot 14$ & \\
\hline V & 0.97 & $0 \cdot 72,1 \cdot 29$ & & $0 \cdot 77$ & $0.55,1.07$ & & 0.52 & $0 \cdot 32,0 \cdot 82$ & & 0.65 & $0.40,1 \cdot 06$ & \\
\hline Household size & & & $<0.001$ & & & 0.010 & & & 0.005 & & & $0 \cdot 010$ \\
\hline One person & 1.00 & - & & 1.00 & - & & 1.00 & - & 0.645 & $1 \cdot 00$ & - & \\
\hline Two persons & 0.98 & $0 \cdot 70,1 \cdot 36$ & & $0.99^{a}$ & $0 \cdot 66,1 \cdot 48$ & & $1 \cdot 12$ & $0 \cdot 79,1 \cdot 60$ & & 0.85 & $0.53,1.34$ & \\
\hline Three persons & $1 \cdot 63$ & $1 \cdot 14,2 \cdot 33$ & & $1 \cdot 13$ & $0 \cdot 73,1 \cdot 74$ & & $1 \cdot 21$ & $0 \cdot 79,1 \cdot 87$ & & $0 \cdot 91$ & $0.50,1.66$ & \\
\hline Four or more persons & $2 \cdot 30$ & $1 \cdot 69,3 \cdot 13$ & & $1 \cdot 56^{\mathrm{b}}$ & $1 \cdot 03,2 \cdot 35$ & & 0.63 & $0.43,0.93$ & & 0.48 & $0.27,0.85$ & \\
\hline \multicolumn{13}{|l|}{ Marital status } \\
\hline Single & $1 \cdot 00$ & - & 0.001 & $1 \cdot 00$ & - & 0.066 & $1 \cdot 00$ & - & 0.042 & $1 \cdot 00$ & - & $0 \cdot 202$ \\
\hline Married/de facto & 0.73 & $0.61,0.88$ & & 0.78 & $0.60,1.02$ & & $1 \cdot 31$ & $1 \cdot 01,1 \cdot 70$ & & $1 \cdot 27$ & $0 \cdot 88,1 \cdot 84$ & \\
\hline Area & & & 0.001 & & & 0.008 & & & & & & \\
\hline Urban & $1 \cdot 00$ & - & & $1 \cdot 00$ & - & & $1 \cdot 00$ & - & 0.645 & $1 \cdot 00$ & - & 0.550 \\
\hline Rural with some urban influence & 0.53 & $0.30,0.92$ & & 0.50 & $0.30,0.83$ & & 0.89 & $0.47,1 \cdot 71$ & & $0 \cdot 82$ & $0.42,1.59$ & \\
\hline Rural with low/no urban influence & 0.51 & $0 \cdot 33,0 \cdot 80$ & & 0.51 & $0 \cdot 32,0 \cdot 80$ & & 0.75 & $0.41,1 \cdot 40$ & & 0.63 & $0 \cdot 33,1 \cdot 19$ & \\
\hline
\end{tabular}

NZEO, New Zealand European and Others; NZDep06, 2006 NZ Index of Deprivation.

a,b Post hoc tests comparing levels of categorical variable. Levels with unlike superscript letters were significantly different $(P<0.05)$.

*Including participants with complete data for all covariates; missing data for education ( $n$ 34), household size $(n 26)$ and marital status $(n 26)$.

tCalculated using survey logistic regression.

$\ddagger$ Calculated using survey logistic regression and adjusted for all other covariates in the table. If the $95 \%$ confidence interval excludes 1.00 , the group is considered significantly different from the referent group

§Overall $P$ value from the Wald test. 
Table 5 Percentage of fast-food and restaurant-food consumers reporting each type of food by sex, ethnic and age groups, 2008/09 New Zealand Adult Nutrition Survey

\begin{tabular}{|c|c|c|c|c|c|c|c|c|c|c|c|c|c|c|}
\hline \multirow[b]{2}{*}{ Food group } & \multirow[b]{2}{*}{ Total (\%) } & \multicolumn{2}{|c|}{ Sex $(\%)$} & \multirow[b]{2}{*}{$P^{*}$} & \multicolumn{3}{|c|}{ Ethnicity (\%) } & \multirow[b]{2}{*}{$P^{\star}$} & \multicolumn{5}{|c|}{ Age group (\%) } & \multirow[b]{2}{*}{$P^{\star}$} \\
\hline & & Males & Females & & NZEO+ & Māori & Pacific & & $15-18$ years & $19-30$ years & $31-50$ years & $51-70$ years & $71+$ years & \\
\hline \multicolumn{15}{|l|}{ Fast foods ( $n$ 1256) } \\
\hline Bread-based dishes & 41 & 44 & 37 & $0 \cdot 153$ & 42 & 36 & 40 & $0 \cdot 482$ & $52^{\mathrm{a}}$ & $48^{a b}$ & $40^{\mathrm{b}}$ & $27^{c}$ & $30^{c}$ & $<0.001$ \\
\hline Sandwiches & 18 & 18 & 17 & 0.910 & 18 & 14 & 13 & $0 \cdot 171$ & 18 & 21 & 15 & 17 & 18 & 0.741 \\
\hline Burgers and hotdogs & 17 & 19 & 14 & 0.083 & 16 & 17 & 19 & 0.689 & $24^{\mathrm{a}}$ & $23^{\mathrm{a}}$ & 15 & $8^{b}$ & $7^{b}$ & 0.001 \\
\hline Pizza & 6 & 7 & 6 & 0.847 & 7 & 5 & 8 & 0.347 & $13^{a}$ & $5^{b}$ & 8 & 3 & 5 & 0.009 \\
\hline Potatoes & 37 & 38 & 35 & 0.331 & $33^{\mathrm{a}}$ & $53^{b}$ & $49^{b}$ & $<0.001$ & 48 & 39 & 37 & 29 & 27 & 0.006 \\
\hline Non-alcoholic beverages & 36 & 35 & 37 & 0.605 & 37 & 32 & 32 & 0.322 & $32^{\mathrm{a}}$ & 37 & 38 & 37 & $14^{\mathrm{b}}$ & $<0.001$ \\
\hline Poultry & 15 & 16 & 14 & 0.661 & $14^{\mathrm{a}}$ & 19 & $26^{\mathrm{b}}$ & 0.005 & 13 & 17 & 16 & 13 & 6 & 0.246 \\
\hline Grains and pasta & 13 & 13 & 13 & 0.925 & 13 & 18 & 9 & 0.046 & 12 & 12 & 11 & 18 & 13 & 0.637 \\
\hline Fish/seafoodł & 12 & 14 & 10 & $0 \cdot 133$ & $11^{\mathrm{a}}$ & $18^{\mathrm{b}}$ & $11^{\mathrm{a}}$ & 0.019 & $6^{a}$ & $8^{\mathrm{ac}}$ & $13^{\mathrm{b}}$ & $18^{\mathrm{bd}}$ & $16^{\mathrm{b}}$ & 0.007 \\
\hline Cakes and muffins & 10 & 9 & 11 & 0.576 & 11 & 7 & 5 & 0.085 & $3^{\mathrm{a}}$ & 8 & $12^{b}$ & $12^{\mathrm{b}}$ & $13^{\mathrm{b}}$ & 0.009 \\
\hline Pies and pasties & 7 & 9 & 5 & 0.096 & 7 & 10 & 9 & 0.320 & 4 & 8 & 7 & 10 & 9 & 0.279 \\
\hline Vegetables $\$$ & 7 & 5 & 9 & 0.042 & 6 & 7 & 9 & 0.464 & 5 & 6 & 7 & 7 & 14 & 0.536 \\
\hline Bread & 5 & 5 & 6 & 0.654 & 5 & 7 & 6 & 0.588 & $4^{\mathrm{a}}$ & 5 & 6 & 4 & $16^{\mathrm{b}}$ & 0.061 \\
\hline \multicolumn{15}{|l|}{ Restaurant foods ( $n$ 498) } \\
\hline Grains and pasta & 21 & 22 & 20 & 0.699 & 21 & 18 & 4 & 0.057 & 30 & 33 & 22 & 11 & 14 & 0.063 \\
\hline Bread-based dishes & 21 & 21 & 21 & 0.990 & 21 & 13 & 14 & $0 \cdot 158$ & 33 & 12 & 19 & 29 & 21 & 0.095 \\
\hline Alcoholic beverages & 22 & 29 & 16 & 0.016 & 21 & 23 & 50 & 0.078 & 22 & 27 & 20 & 19 & 26 & 0.798 \\
\hline Non-alcoholic beverages & 50 & 46 & 53 & 0.246 & 50 & 49 & 40 & 0.765 & 55 & 43 & 48 & 57 & 46 & 0.488 \\
\hline Cakes and muffins & 20 & 12 & 27 & $<0.001$ & 20 & 27 & 14 & 0.520 & $7^{a}$ & $9^{a}$ & $16^{\mathrm{a}}$ & $30^{\mathrm{b}}$ & $31^{\mathrm{b}}$ & 0.001 \\
\hline Potatoes & 22 & 23 & 22 & 0.839 & 23 & 21 & 20 & 0.914 & 25 & 30 & 18 & 21 & 26 & 0.439 \\
\hline Vegetables & 30 & 30 & 30 & 0.978 & 32 & 18 & 18 & 0.021 & 26 & 26 & 31 & 32 & 33 & 0.867 \\
\hline Fish/seafood & 10 & 9 & 12 & 0.652 & 11 & 10 & 2 & 0.403 & 11 & 10 & 2 & 13 & 10 & 0.834 \\
\hline Bread & 12 & 16 & 10 & $0 \cdot 146$ & 12 & 14 & 19 & 0.581 & 25 & 21 & 9 & 10 & 12 & 0.091 \\
\hline Pies & 6 & 6 & 5 & 0.714 & 5 & 11 & 2 & 0.117 & 5 & 4 & 6 & 6 & 9 & 0.633 \\
\hline
\end{tabular}

a,b,c,d Values with within rows unlike superscript letters were significantly different $(P<0.05)$

*Overall $P$ value from unadjusted logistic regression.

+New Zealand European and Others.

Sincludes salads, e.g. 
Similar to our findings, in the USA Kim and Leigh found a positive association between household size and fast-food use, and a negative association between household size and restaurant use ${ }^{(11)}$. Qualitative research has indicated that time constraints and the use of convenience foods are interrelated, and are also influenced by family dynamics, such as the number of adults within the household and external stressors such as work commitments ${ }^{(33,34)}$. Perceived time pressures were noted as being important in the purchase of takeaway meals in Ireland ${ }^{(35)}$. We also found a tendency for participants not living with a partner or a spouse to be more likely to report fast food compared with those living with a partner or a spouse. This is consistent with two US studies ${ }^{(31,36)}$ and a UK study ${ }^{(32)}$. It is possibly reflective of those living alone being less inclined to cook for themselves ${ }^{(35)}$.

Previous national nutrition surveys in NZ have not collected information on where food is sourced and we are therefore unable to examine time trends. Recent research from the USA indicates there has been a levelling off of energy from foods sourced from outside the home ${ }^{(37)}$. This is congruent with a stabilisation in the amount of time spent in food preparation and cooking between 1992 and $2008^{(37)}$. It is unclear whether in NZ use of fast food and restaurant food has peaked or will rise further. The need for convenience is unlikely to decrease, and therefore the challenge is to provide solutions that are both nutritious and quick.

Consistent with other NZ research ${ }^{(13)}$, Māori were more likely to consume fast food compared with NZEO, and they were less likely to report restaurant food. Information was not collected on where food was eaten (either at home or where it was purchased) but it may indicate a preference for Māori to consume food within their home.

Documenting the types of foods consumed is important in helping prioritise public health strategies, both at a national level and also initiatives targeting subgroups of the population. It appears the traditional NZ takeaway of fish and chips is being superseded by bread-based dishes, particularly in the younger age groups. Typical fast foods in NZ have been shown to be higher in sodium in comparison to the UK, where the food industry is actively reducing salt levels in response to the wider Food Standards Agency salt reduction campaign ${ }^{(38)}$. A successful example of efforts to reformulate in NZ is the partnership between the NZ Heart Foundation and the Ministry of Health with potato growers, chip manufacturers and oil suppliers (The Chip Group). The goal of this group is to reduce total fat, saturated fat and salt content of potato chips (French fries) served by the NZ food industry ${ }^{(39)}$. A similar initiative targeting the nutrient profile of bread-based dishes such as burgers and pizzas could also be an effective intervention.

Following an audit of the major fast-food chains in NZ, Chand et al. recommended an increase in the range of healthier options available to improve the overall nutritional quality of fast-food menus ${ }^{(40)}$. Our data further support this recommendation. Vegetables were reported by a higher percentage of restaurant-food consumers compared with fast-food consumers, possibility because of the greater availability and variety of vegetables and dishes on offer at restaurants compared with fastfood outlets.

Overall one-third of fast-food consumers and one-half of restaurant food consumers reported a non-alcoholic beverage. Beverages are important to consider since they have the potential to contribute to energy intake. As only $10 \%$ of the soft drinks sourced from fast-food takeaway outlets were diet (data not presented), there is potential to encourage consumers towards this choice or water rather than regular soft drinks in order to reduce overall energy intake from these meals.

A major strength of the present study is that both fast food and restaurant food have been investigated and the source of the food has been investigated rather than the place of consumption. However, potential limitations should also be acknowledged. We have not captured all types of foods prepared outside the home as it is possible to purchase foods such as sandwiches, hot chips and pies from supermarkets and small local shops in NZ. This has also been highlighted as a limitation of the NHANES coding scheme for food sources ${ }^{(19)}$. Suggestions have been made that further research in this area disaggregates 'stores' (shops), which would provide further information on the source of food ${ }^{(19)}$. Furthermore, in the current study, foods purchased from workplace cafeteria or canteens were not included. This is because we were unable to discern whether the food was sourced from colleagues or purchased from cafeterias or canteens.

A single $24 \mathrm{~h}$ diet recall does not capture usual intake; however, means are adequate for making comparisons between large subgroups of the population ${ }^{(41)}$. As with other types of self-reported dietary assessment, underreporting may be an issue ${ }^{(41)}$. There is evidence that less socially desirable foods, such as those higher in sugar and fat, are more likely to be under-reported ${ }^{(42)}$, which may have resulted in an underestimation of fast-food intake.

A final limitation is that although socio-economic status was assessed using both education as an individual measure and NZ Dep06 quintile as an area-based measure, they do not completely capture socio-economic position ${ }^{(43)}$. Some residual confounding may be present in the adjusted models, e.g. due to the effects of household income (not measured).

The demographic characteristics associated with consumption of foods prepared outside the home were different depending on where the food was sourced. This is important to consider for those investigating the impact of food prepared outside the home on health outcomes. Socio-economic confounders may differ depending on the source of food being investigated. 


\section{Conclusion}

In conclusion, the present study is the first one in NZ to quantify the energy contribution of fast food and restaurant foods, and it provides comprehensive detail on demographic associations with their use and information on the types of foods consumed. Individual factors such as ethnicity, household size, age, sex and marital status were found to be important influences on the use of fast food and restaurant food. For young adults, fast food and restaurant foods were a significant component of their overall diet. Further monitoring and longitudinal studies are required to investigate whether this cohort continues with current levels of consumption. In addition, further investigation is needed to establish specific factors contributing to the higher reported intake of fast food in Māori.

From this research several recommendations can be made. There is clearly a need for nutritious, cheap and fast options for time-poor families irrespective of socio-economic status. A greater incorporation of under-represented food groups, such as fruit and vegetables, into fast-food menus would help improve the overall nutritional quality of the food on offer. Further partnerships with industry, with a focus to reformulate the most commonly consumed fast foods, should also be considered. Health promotion initiatives should also encourage the selection of healthier choices, with targeting of subgroups of the population who are more likely to consume fast foods such as males and young adults.

\section{Acknowledgements}

Sources of funding: The data used in this study were from the 2008/09 New Zealand Adult Nutrition Survey (NZANS 2008/09). The New Zealand Ministry of Health funded the survey, and the survey was conducted collaboratively with the University of Otago. The New Zealand Ministry of Health had no role in the design, analysis or writing of this article. The New Zealand Crown is the owner of the copyright for the survey data. The results presented in this paper are the work of the authors. Conflicts of interest: The authors declare they have no conflict of interest. Ethics: The study received ethical approval from the NZ Health and Disability Multi-Region Ethics Committee (MEC/08/04/049). Authors' contributions: W.R.P. was a Principal Investigator and E.A.F. a Nutritionist on the NZANS 2008/09. C.S., W.R.P. and A.R.G., study design and conception; E.A.F. and W.R.P., nutrient matching; C.S., statistical analysis, drafting of manuscript; A.R.G., statistical advice; C.S., W.R.P., A.R.G. and E.A.F., interpretation of data, revision of manuscript. Acknowledgements: The authors would like to thank C. Blakey, Department of Human Nutrition, University of Otago for his programming services and $\mathrm{H}$. Walker for statistical advice. The authors would also like to thank the New Zealanders who willingly participated in the survey and the dedicated input of the field and project teams.

\section{References}

1. Smoyer-Tomic KE, Spence JC, Raine KD et al. (2008) The association between neighborhood socioeconomic status and exposure to supermarkets and fast food outlets. Health Place 14, 740-754.

2. Pearce J, Blakely T, Witten K et al. (2007) Neighborhood deprivation and access to fast-food retailing. Am J Prev Med 32, 375-382.

3. Fleischhacker SE, Evenson KR, Rodriguez DA et al. (2010) A systematic review of fast food access studies. Obes Rev 12, 460-471.

4. Fraser LK, Edwards KL, Cade J et al. (2010) The geography of fast food outlets: a review. Int J Environ Res Public Health 7, 2290-2308.

5. Jeffery RW, Baxter J, McGuire M et al. (2006) Are fast food restaurants an environmental risk factor for obesity? Int $J$ Behav Nutr Phys Act 3, 2.

6. Bowman SA \& Vinyard BT (2004) Fast food consumption of US adults: impact on energy and nutrient intakes and overweight status. J Am Coll Nutr 23, 163-168.

7. French SA, Harnack L \& Jeffery RW (2000) Fast food restaurant use among women in the Pound of Prevention study: dietary, behavioral and demographic correlates. Int J Obes Relat Metab Disord 24, 1353-1359.

8. Burns C, Jackson M, Gibbons C et al. (2002) Foods prepared outside the home: association with selected nutrients and body mass index in adult Australians. Public Health Nutr 5, 441-448.

9. Orfanos P, Naska A, Trichopoulos D et al. (2007) Eating out of home and its correlates in 10 European countries. The European Prospective Investigation into Cancer and Nutrition (EPIC) study. Public Health Nutr 10, $1515-1525$.

10. Simmons D, McKenzie A, Eaton S et al. (2005) Choice and availability of takeaway and restaurant food is not related to the prevalence of adult obesity in rural communities in Australia. Int J Obes Relat Metab Disord 29, 703-710.

11. Kim D \& Leigh JP (2011) Are meals at full-service and fastfood restaurants 'normal' or 'inferior'? Popul Health Manag 14, 307-315.

12. Statistics New Zealand (2012) Household Economic Survey: Year ended June 2012. http://www.stats.govt.nz/ browse_for_stats/people_and_communities/Households/ HouseholdEconomicSurvey_HOTPYeJun12.aspx (accessed January 2013)

13. Murray SJ (2012) Shopping Behaviours of New Zealand Households. Wellington: Health Sponsorship Council.

14. University of Otago \& Ministry of Health (2011) Methodology Report for the 2008/09 New Zealand Adult Nutrition Survey. Wellington: Ministry of Health.

15. Salmond C, Crampton P \& Atkinson J (2007) NZDep2006 Index of Deprivation User's Manual. Dunedin: Department of Public Health, University of Otago.

16. Statistics New Zealand (2012) Geographic Hierarchy. http://www.stats.govt.nz/surveys_and_methods/methods/ classifications-and-standards/geographic-hierarchy.aspx (accessed December 2012).

17. Statistics New Zealand (2007) New Zealand: An Urban/ Rural Profile Update. http://www.stats.govt.nz/browse_ for_stats/people_and_communities/geographic-areas/urbanrural-profile-update.aspx (accessed December 2012).

18. Binkley JK (2006) The effect of demographic, economic, and nutrition factors on the frequency of food away from home. J Consum Aff 40, 372-391. 
19. Drewnowski A \& Rehm CD (2013) Energy intakes of US children and adults by food purchase location and by specific food source. Nutr J 12, 59 .

20. 3 News (2012) Health group calls for fast food restrictions. http://www.3news.co.nz/Health-group-calls-for-fast-foodrestrictions/tabid/423/articleID/242047/Defaultaspx (accessed June 2013).

21. Thornton LE, Bentley RJ \& Kavanagh AM (2011) Individual and area-level socioeconomic associations with fast food purchasing. J Epidemiol Community Health 65, 873-880.

22. Miura K, Giskes K \& Turrell G (2009) Socioeconomic differences in takeaway food consumption and their contribution to inequalities in dietary intakes. $J$ Epidemiol Community Health 63, 820-826.

23. Paeratakul S, Ferdinand DP, Champagne CM et al. (2003) Fast-food consumption among US adults and children: dietary and nutrient intake profile. J Am Diet Assoc 103, $1332-1338$

24. Smith C, Parnell W \& Brown R (2010) Family Food Environment: Barriers to Acquiring Affordable and Nutritious Food in New Zealand Households. Wellington: Families Commission.

25. Lachat C, Nago E, Verstraeten R et al. (2012) Eating out of home and its association with dietary intake: a systematic review of the evidence. Obes Rev 13, 329-346.

26. Richardson AS, Boone-Heinonen J, Popkin BM et al. (2011) Neighborhood fast food restaurants and fast food consumption: a national study. BMC Public Health 11, 543.

27. Thornton LE, Jeffery RW \& Crawford DA (2012) Barriers to avoiding fast-food consumption in an environment supportive of unhealthy eating. Public Health Nutr (Epublication ahead of print version).

28. van der Horst K, Brunner TA \& Siegrist M (2011) Fast food and take-away food consumption are associated with different lifestyle characteristics. J Hum Nutr Diet 24, 596-602.

29. Mohr P, Wilson C, Dunn K et al. (2007) Personal and lifestyle characteristics predictive of the consumption of fast foods in Australia. Public Health Nutr 10, 1456-1463.

30. Dunn KI, Mohr P, Wilson CJ et al. (2011) Determinants of fast-food consumption. An application of the theory of planned behaviour. Appetite 57, 349-357.

31. Dave JM, An LC, Jeffery RW et al. (2009) Relationship of attitudes toward fast food and frequency of fast-food intake in adults. Obesity (Silver Spring) 17, 1164-1170.
32. Olsen KW, Warde A \& Martens L (2000) Social differentiation and the market for eating out in the UK. Hospitality Manag 19, 173-190.

33. Devine CM, Jastran M, Jabs J et al. (2006) 'A lot of sacrifices': work-family spillover and the food choice coping strategies of low-wage employed parents. Soc Sci Med 63, 2591-2603.

34. Bava CM, Jaeger SR \& Park J (2008) Constraints upon food provisioning practices in busy women's lives: trade-offs which demand convenience. Appetite 50, 486-498.

35. de Boer M, McCarthy M, Cowan C et al. (2004) The influence of lifestyle characteristics and beliefs about convenience food on the demand for convenience foods in the Irish market. Food Qual Prefer 15, 155-165.

36. Satia JA, Galanko JA \& Siega-Riz AM (2004) Eating at fast-food restaurants is associated with dietary intake, demographic, psychosocial and behavioural factors among African Americans in North Carolina. Public Health Nutr 7 , 1089-1096.

37. Smith LP, Ng SW \& Popkin BM (2013) Trends in US home food preparation and consumption: analysis of national nutrition surveys and time use studies from 1965-1966 to 2007-2008. Nutr J 12, 45.

38. Dunford E, Webster J, Woodward M et al. (2012) The variability of reported salt levels in fast foods across six countries: opportunities for salt reduction. CMAJ 184, 1023-1028.

39. The Chip Group (editor) (2010) Industry Standards. http://www.chipgroup.co.nz/industry-standards/default.aspx (accessed June 2013)

40. Chand A, Eyles H \& Ni Mhurchu CN (2012) Availability and accessibility of healthier options and nutrition information at New Zealand fast food restaurants. Appetite 58, $227-233$

41. Institute of Medicine (2000) Dietary Reference Intakes: Applications in Dietary Assessment. Washington, DC: National Academy Press.

42. Heitmann BL, Lissner L \& Osler M (2000) Do we eat less fat, or just report so? Int J Obes Relat Metab Disord 24, 435-442.

43. Blakely $\mathrm{T}$ (2004) Confounding by socioeconomic position remains after adjusting for neighbourhood deprivation: an example using smoking and mortality. J Epidemiol Community Health 58, 1030-1031. 